\title{
ESTIMATING FACULTY AND STUDENT WORKLOAD FOR INTERACTION IN ONLINE GRADUATE MUSIC COURSES
}

\author{
Barbara Payne McLain \\ University of Hawaii - Manoa
}

\begin{abstract}
Research suggests that faculty perceive greater workload for online teaching. These perceptions have little quantitative support. This study utilized seven online graduate courses, over a three year period to estimate faculty and student workload for interaction via online discussions and electronic mail using average reading and typing speeds. Weekly faculty workload estimates for interaction did not exceed normal expectations for faculty "office hours" for six of the seven courses. Perceptions of excessive workload for communication may be better explained by the dynamics of online interaction found in this study. Online students attempted to contact their instructors, twenty-four hours per day, seven days per week, at least every fourteen hours. Further research is needed to establish the time needed for FTF teaching interaction and to validate actual typing and reading speeds for more accurate estimates of the time needed for online course interaction.
\end{abstract}

\section{KEYWORDS}

Faculty Workload, Interaction, Workload Dynamics, Online Course, Distance Education, Internet Course, Music.

\section{INTRODUCTION}

The scope and number of internet-based distance learning programs in American colleges and universities continues to increase each year. Established measures of faculty workload and compensation are being challenged by distance learning faculty and their labor unions, who assert that development of online courses is not a normal faculty activity, and online teaching takes more time and effort [1]. Because of a lack of precedents and substantive research, compensation models for online teaching workload and course development vary erratically across the country [2].

One of the conflicts in the online teaching workload debate concerns interaction. Most experts and accrediting guidelines maintain that interaction is a vital component in successful online learning. Oncampus class sessions contain blended interactions, with a percentage of time spent in content presentation via lectures, intermingled with announcements and active student participation. Instruction time outside of the traditional class includes administrative duties, grading, preparation of materials or lectures, and communication with students via email, phone or in person. No research was found which provided data regarding faculty workload for interaction in FTF (face-to-face) instruction.

While few would argue against the benefits of interaction, this emphasis is puzzling given that traditional academic classrooms continue to utilize a passive lecture model with interaction limited to only occasional discussions or questions from students [3, 4]. Some might argue that online learning is already a completely active process, much different from its passive traditional counterpart. Online students 
engage and control the flow of information, as well as their participation frequency and level, at all times.

The differences between online and FTF teaching environments make comparisons difficult and measurement tools problematic. Qualitative surveys of perceptions about the time needed for online teaching may not satisfy those responsible for determining faculty compensation. While perceptions of workload may be a strong factor in faculty reactions to the online teaching environment, little quantitative data is available to support these perceptions. Quantitative research concerning workload for online teaching also may be biased by the data collection process, which may require that online faculty log activity related to online teaching, thereby adding additional tasks to their workload.

\section{A. Online Course Interaction}

Students appear to value interaction in online courses. Several researchers reported positive student perceptions of increased interaction in online courses $[5,6,7,8,9]$. Students also perceived online interactions to improve learning $[10,11]$. Tello determined a strong correlation between frequency of online interactions and positive student perceptions or persistence in fifty-two online courses offered at a public university [12]. Wu \& Hiltz also found student perceptions concerning motivation and increased learning correlated positively to online interaction [13].

Prammanee analyzed the written discussion posts from nineteen students in a single online course during four, one-week periods. He found a total class average of forty posts utilizing an average of 6,267 words per week. Student discussion posts consisted of an average of one post per week using an average of 134 words [14]

Lazarus utilized a stopwatch to determine faculty workload for grading assignments, creating or reading mail and discussions in three online courses. Her data indicated that workload for teaching online courses was not excessive, requiring from 3.5 to 7.0 hours per week [15].

\section{B. Comparing FTF and Online Interaction}

Comparisons of faculty or student perceptions of online and traditional classrooms have provided mixed results. Some researchers found significant increases in perceived interaction or more positive perceptions in online environments $[16,7,17]$. Other studies found no significant differences regarding interaction in the two environments $[18,19]$ or better interaction in traditional classrooms [20, 21, 22, 23]. Still other researchers reported conflicting results when comparing traditional and online course interaction [24, 25, 26, 27].

Hislop compared workload logs from online instructors and determined that online teaching took more time than FTF classes and that this time was spread out over the entire week. Online sections of each course involved 30\% more days than FTF sections of the same course [28].

\section{METHOD}

The purpose of this study was to estimate faculty and student workload and workload dynamics for online course interaction. Online interaction was defined as discussion board posts and email sent to, or received from students. WebCT provides the means to archive all discussion posts and internal email. These text interactions were extracted for each student and instructor in the seven courses. Only interactions from students who completed each course were included in the study. Some courses provided an optional 
casual discussion forum which was excluded from the study. Only discussion interactions related to course announcements and required content were analyzed.

Only the body text of each interaction was included in subsequent data analysis. All information regarding the subject of messages, and identifiers such as name, message number, and date, and all quoted text were deleted from each archive. Data concerning the number of interactions, and words used in discussion postings and email messages was calculated for each subject and course. Mail messages from the instructor to the entire class were counted only once in calculations. Mail messages sent between students also were excluded from the study. Word counts for all mail and discussion posts were compiled for further analysis.

Workload equivalents were defined as a combination of the estimated time needed for creating (typing) and processing (reading) interactions using average reading and typing speed in words per minute (wpm). For the purposes of this study, workload was calculated using an average typing speed of 40 wpm [29] and an average reading speed of printed text of $250 \mathrm{wpm}$ [30].

Workload dynamics were defined as frequency of student contact via WebCT mail and percentage of messages sent to instructors during non-traditional work hours. Non-traditional work hours were defined as weekends, holidays and weekdays before 8AM and after 5PM. Mail messages received by each instructor were analyzed using a 24-hour clock beginning with the first message received in each course, for mean elapsed time between messages, mean number of messages received per day, and percentage of messages received during weekends, holidays or non-traditional weekday working hours (before 8AM and after 5PM).

The study population utilized seven asynchronous online graduate music courses at the University of Hawaii offered between Fall 2001 and Summer 2004. These courses were required in a newly developed online option for students pursuing a Master of Arts degree in music education. All courses utilized WebCT courseware and interaction was a required component in six of the seven classes via the course discussion board. Course "E" was a library skills class and did not require regular discussion board participation. WebCT email was used extensively for communication in all seven courses. Courses varied in duration from four weeks (summer intensive) to sixteen weeks (full semester). Subjects $(\mathrm{N}=72)$ included a total of sixty-nine graduate students who participated in the courses taught by three faculty members.

\section{RESULTS}

The number of students in each of the seven online courses ranged from seven to fourteen. Online course durations varied from four weeks to sixteen weeks. Courses of shorter duration were offered in an intensive summer format. Interaction during these courses was defined as WebCT mail messages and discussion posts. The total number of student-created discussions ranged from eighty-eight to 592 posts. Online faculty contributions to required discussions ranged from a low of twenty-nine posts to a high of 109 posts. The mean number of student discussions ranged from a low of 1.05 posts, to a high of 9.68 posts per week. Total mean student discussion posts during these courses ranged from 6.29 posts (course without a discussion requirement) to 74.00 posts (See Table 1). 
Table 1. Total and Mean Number of Discussion Board Posts for Students and Faculty in Seven Graduate Asynchronous Online Music Courses.

\begin{tabular}{|c|c|c|c|c|c|c|c|}
\hline 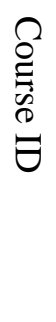 & 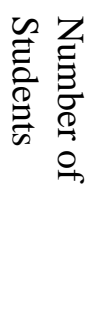 & 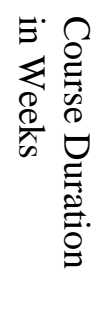 & 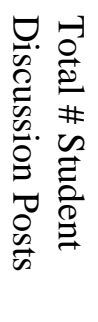 & 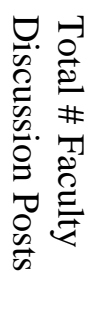 & 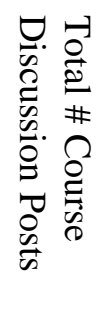 & 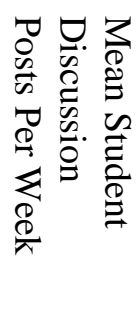 & 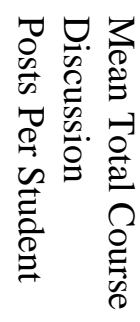 \\
\hline A & 8 & 16 & 592 & 88 & 680 & 4.63 & 74.00 \\
\hline B & 7 & 5 & 291 & 50 & 341 & 8.31 & 41.57 \\
\hline $\mathrm{C}$ & 7 & 4 & 271 & 29 & 300 & 9.68 & 38.71 \\
\hline $\mathrm{D}$ & 12 & 16 & 515 & 107 & 622 & 3.39 & 42.92 \\
\hline$E$ & 14 & 6 & 88 & 43 & 131 & 1.05 & 6.29 \\
\hline $\mathrm{F}$ & 10 & 6 & 199 & 42 & 241 & 3.32 & 19.90 \\
\hline $\mathrm{G}$ & 11 & 7 & 555 & 109 & 664 & 3.15 & 50.00 \\
\hline
\end{tabular}

Faculty and students communicated extensively using WebCT mail in all courses. In all but one course, faculty sent more messages and more total words to students than they received. Mean number of messages sent to faculty ranged from 1.50 to 4.45 messages per week. Faculty sent from 135 to 850 total mail messages to students. Generally speaking, classes of shorter duration resulted in fewer mail messages per course.

Workload for creating mail messages and discussions was estimated using an average typing speed of 40 wpm [29]. Estimated workload for creating WebCT mail messages during all courses was higher for online faculty than students. Student total workload estimates for creating online mail were under one hour for all courses. Estimates of faculty workload for creating mail messages ranged from 2.78 hours to 15.73 hours over the duration of each course (See Table 2).

Table 2. Faculty and Student Total and Mean Workload Estimates for Creating WebCT Email Based on Average Typing Speed of 40 WPM

\begin{tabular}{|c|c|c|c|c|c|c|c|c|}
\hline 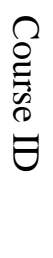 & 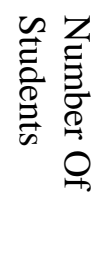 & 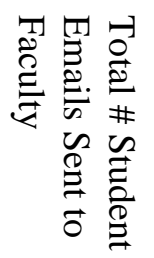 & 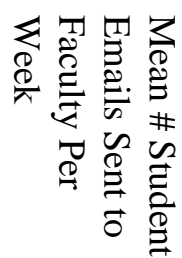 & 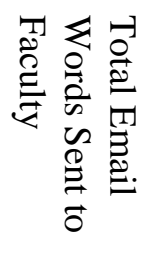 & 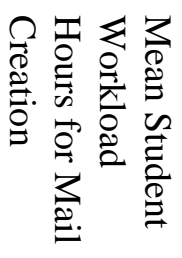 & 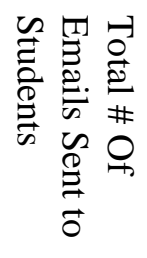 & 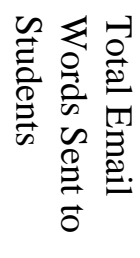 & 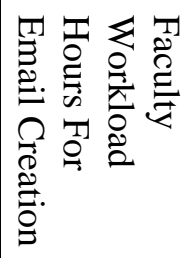 \\
\hline $\mathrm{A}$ & 8 & 190 & 1.50 & 18,969 & .99 & 215 & 17,099 & 7.12 \\
\hline$B$ & 7 & 156 & 4.45 & 5,806 & .32 & 157 & 7,888 & 3.29 \\
\hline $\mathrm{C}$ & 7 & 116 & 4.14 & 6,473 & .39 & 135 & 6,643 & 2.78 \\
\hline $\mathrm{D}$ & 12 & 369 & 1.92 & 20,552 & .71 & 674 & 24,088 & 10.04 \\
\hline $\mathrm{E}$ & 14 & 369 & 4.39 & 15,933 & .47 & 623 & 33,828 & 14.10 \\
\hline $\mathrm{F}$ & 10 & 142 & 2.37 & 7,295 & .30 & 254 & 7,970 & 3.32 \\
\hline$G$ & 11 & 454 & 2.58 & 25,696 & .97 & 850 & 37,753 & 15.73 \\
\hline
\end{tabular}


Creating course discussions took more time in each course than creating mail messages for both students and faculty. Total number of discussion words created by both students and faculty ranged from a low of 11, 432 words to a high of 93,151 words. The mean number of student discussion words created each week ranged from approximately 136 to 1,286 words. Estimated mean student workload hours for creating discussions ranged from less than one hour (Course E) to 4.85 hours (Course A). Faculty workload estimates for creating discussions ranged from 1.5 to 9.8 hours per course (See Table 3.).

Table 3. Faculty and Student Total and Mean Workload Estimates for Creating Required Course Discussions Based on Average Typing Speed of 40 WPM

\begin{tabular}{|c|c|c|c|c|c|c|c|}
\hline 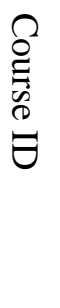 & 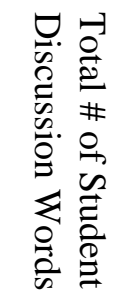 & 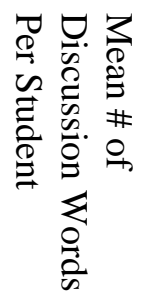 & 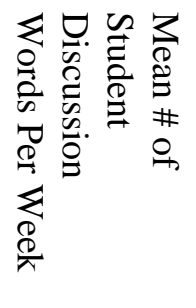 & 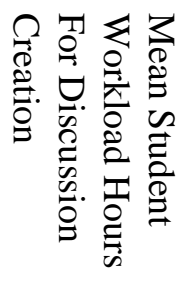 & 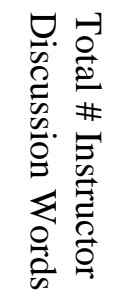 & 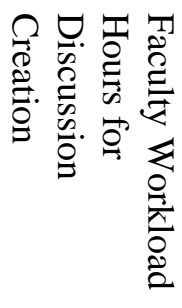 & 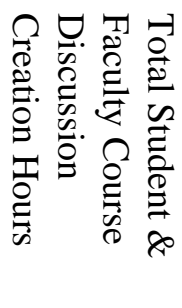 \\
\hline A & 93,151 & 11,643 & 727.74 & 4.85 & 11,485 & 4.79 & 43.60 \\
\hline B & 28,904 & 4,129 & 825.82 & 1.72 & 6,020 & 2.51 & 14.55 \\
\hline $\mathrm{C}$ & 35,997 & 5,142 & $1,285.54$ & 2.14 & 4,545 & 1.89 & 16.89 \\
\hline $\mathrm{D}$ & 70,476 & 5,873 & 367.09 & 2.45 & 18,500 & 7.71 & 37.07 \\
\hline$E$ & 11,432 & 816 & 136.07 & 0.34 & 5,925 & 1.50 & 7.23 \\
\hline $\mathrm{F}$ & 33,514 & 3,351 & 558.57 & 1.40 & 9.484 & 3.95 & 17.92 \\
\hline G & 87,257 & 7,932 & 495.78 & 3.31 & 25,753 & 9.82 & 46.18 \\
\hline
\end{tabular}

Workload estimates for reading mail and discussions were based on an average reading speed of 250 WPM [29]. In all classes, estimated student workload for reading WebCT mail was one hour or less for the entire course. Estimated faculty workload for reading mail ranged from approximately one-half hour to 1.71 hours during the course (See Table 4). Required discussion workload was assumed to be equal for students and faculty since both were expected to read all posts regardless of their source. Estimated student and faculty workload for reading course discussions ranged from 1.16 hours to 7.39 hours (See Table 5.)

Table 4. Faculty \& Student Workload Total Course Estimates for Reading WebCT Email Based on Average Reading Speed of 250 WPM

\begin{tabular}{|c|c|c|c|c|}
\hline $\begin{array}{l}0 \\
\stackrel{0}{E} \\
0 \\
0 \\
\theta\end{array}$ & 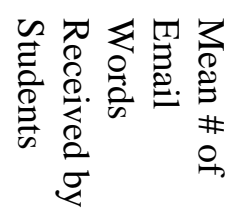 & 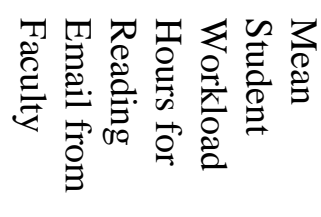 & 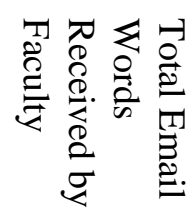 & 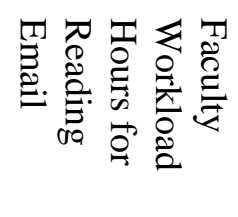 \\
\hline A & 2,188 & .15 & 18,969 & 1.26 \\
\hline$B$ & 1,401 & .09 & 5,806 & .39 \\
\hline $\mathrm{C}$ & 1,246 & .08 & 6,473 & .43 \\
\hline $\mathrm{D}$ & 6,208 & .40 & 20,552 & 1.37 \\
\hline$E$ & 3,144 & .21 & 15,933 & 1.06 \\
\hline $\mathrm{F}$ & 2,297 & .15 & 7,295 & .49 \\
\hline$G$ & 9,271 & .60 & 25,696 & 1.71 \\
\hline
\end{tabular}


Table 5. Total Course Workload Estimates for Students and Faculty for Reading Course Discussion Boards Based on Average Reading Speed of 250 WPM

\begin{tabular}{|c|c|c|}
\hline 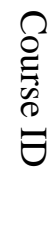 & 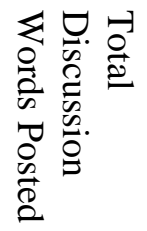 & 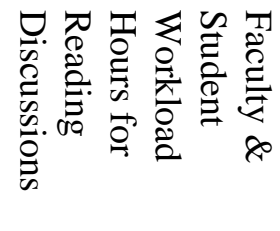 \\
\hline $\mathrm{A}$ & 104,636 & 6.98 \\
\hline B & 34,924 & 2.32 \\
\hline $\mathrm{C}$ & 40,542 & 2.70 \\
\hline $\mathrm{D}$ & 88,976 & 5.93 \\
\hline $\mathrm{E}$ & 17,357 & 1.16 \\
\hline $\mathrm{F}$ & 42,998 & 2.87 \\
\hline$G$ & 110,832 & 7.39 \\
\hline
\end{tabular}

Workload estimates for creating or reading mail and discussions were then combined for each class to estimate total interaction workload during the course. Estimated total student interaction workloads ranged from 2.18 hours to 12.97 hours. Weekly mean estimates for student interaction workload ranged from approximately one-half hour to 1.75 hours (See Table 6.).

Table 6. Estimated Mean Course Interaction Workload Hours for Online Students

\begin{tabular}{|c|c|c|c|c|c|c|c|}
\hline $\begin{array}{l}\text { O } \\
\stackrel{\Xi}{0} \\
\stackrel{D}{\Xi}\end{array}$ & 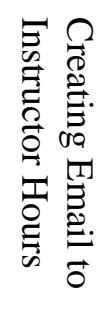 & 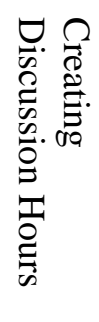 & 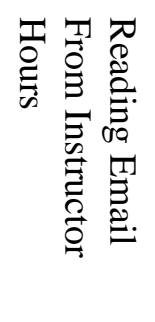 & 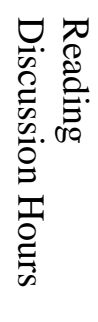 & 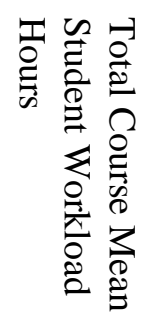 & 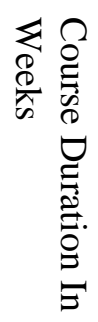 & 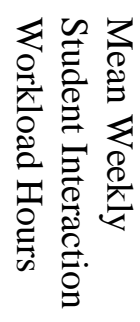 \\
\hline A & .99 & 4.85 & .15 & 6.98 & 12.97 & 16 & .81 \\
\hline B & .32 & 1.72 & .09 & 2.32 & 4.45 & 5 & .89 \\
\hline $\mathrm{C}$ & .39 & 2.14 & .08 & 2.70 & 5.31 & 4 & 1.32 \\
\hline $\mathrm{D}$ & .71 & 2.45 & .40 & 5.93 & 9.49 & 16 & .59 \\
\hline $\mathrm{E}$ & .47 & 0.34 & .21 & 1.16 & 2.18 & 6 & .36 \\
\hline $\mathrm{F}$ & .30 & 1.40 & .15 & 2.87 & 4.72 & 6 & .78 \\
\hline $\mathrm{G}$ & .97 & 3.31 & .60 & 7.39 & 12.27 & 7 & 1.75 \\
\hline
\end{tabular}

In all classes, faculty total workload estimates for interaction exceeded that of students. Estimated total faculty workload time for interaction ranged from 7.8 hours to 34.65 hours during their online course. Faculty workload interaction mean estimates ranged from 1.26 to 4.95 hours per week (See Table 7.) 
Table 7. Estimated Course Interaction Workload Hours for Online Faculty.

\begin{tabular}{|c|c|c|c|c|c|c|c|}
\hline 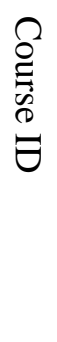 & 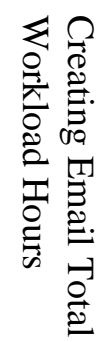 & 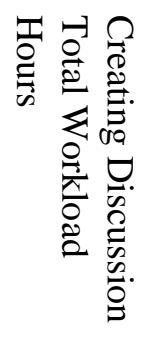 & 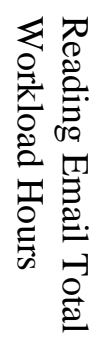 & 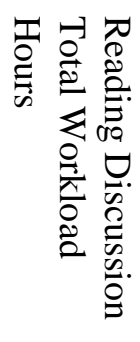 & 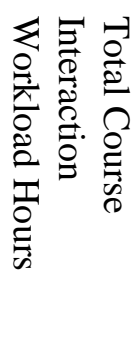 & 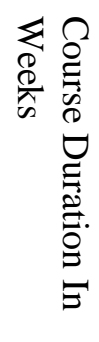 & 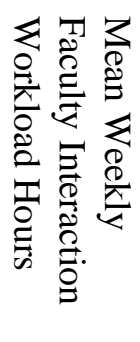 \\
\hline A & 7.12 & 4.79 & 1.26 & 6.98 & 20.15 & 16 & 1.26 \\
\hline B & 3.29 & 2.51 & .39 & 2.32 & 8.51 & 5 & 1.70 \\
\hline $\mathrm{C}$ & 2.78 & 1.89 & .43 & 2.70 & 7.80 & 4 & 1.95 \\
\hline $\mathrm{D}$ & 10.04 & 7.71 & 1.37 & 5.93 & 25.05 & 16 & 1.56 \\
\hline$E$ & 14.10 & 1.50 & 1.06 & 1.16 & 17.82 & 6 & 2.97 \\
\hline $\mathrm{F}$ & 3.32 & 3.95 & .49 & 2.87 & 10.63 & 6 & 1.77 \\
\hline$G$ & 15.73 & 9.82 & 1.71 & 7.39 & 34.65 & 7 & 4.95 \\
\hline
\end{tabular}

To further examine perceptions of increased workload for online faculty, WebCT mail messages were analyzed to determine how frequently online students contacted faculty and how often that contact took place during non-traditional working hours (weekdays before 8AM, weekdays after 5PM, weekends and holidays). Faculty in these online courses received an average of 1.63 to 8.17 mail messages per day. Online faculty often received mail messages throughout every 24-hour period, seven days per week, with mean elapsed time between messages ranging from a low of 2.87 hours to a high of 14.33 hours between mail messages. A majority of all mail messages (> 60\%) were sent to faculty during non-traditional working hours (See Table 8).

Table 8. Workload Dynamics for WebCT Mail Messages Received By Online Faculty

\begin{tabular}{|c|c|c|c|c|}
\hline 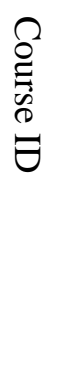 & 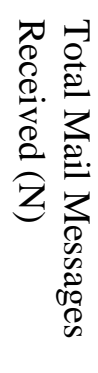 & 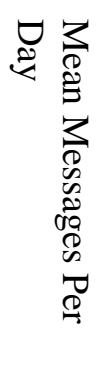 & 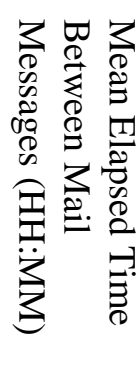 & 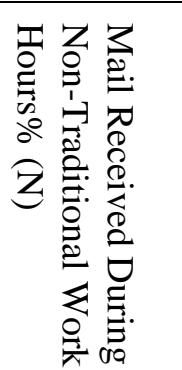 \\
\hline $\mathrm{A}$ & 195 & 1.63 & $14: 33$ & 73\% (143) \\
\hline B & 161 & 4.47 & $5: 34$ & $65 \%$ (104) \\
\hline $\mathrm{C}$ & 126 & 3.60 & $6: 47$ & $65 \% \quad(82)$ \\
\hline $\mathrm{D}$ & 449 & 3.59 & $6: 52$ & $67 \%(300)$ \\
\hline$E$ & 376 & 8.17 & $2: 87$ & $66 \%(250)$ \\
\hline $\mathrm{F}$ & 170 & 3.54 & $6: 36$ & 61\% (104) \\
\hline G & 479 & 4.35 & $5: 82$ & $72 \%(343)$ \\
\hline
\end{tabular}




\section{SUMMARY AND CONCLUSIONS}

Previous research efforts have predominantly shown faculty perceive workload to be greater in online courses than traditional classrooms. This perception was not supported by the interaction workload estimates utilized in this study. Weekly faculty workloads for interaction did not exceed normal expectations for faculty "office hours" for six of the seven courses. Only course "G" required more than three weekly hours for student interaction.

Perceptions of excessive workload may be better explained by the dynamics of online interaction indicated in this study. Online students attempted to contact their instructors, twenty-four hours per day, seven days per week, at least every fourteen hours. This was true regardless of class size or course duration. This is a radical shift from the traditional office hours and face-to-face interaction normally experienced by university faculty. Students do not phone their professors at 3A.M. to ask a question, or visit the professor's office on a weekend or holiday expecting assistance. Online students clearly have no limits on how often, or when, they attempt to interact with their instructors. This change of work "flow" for online faculty, who attempt to respond to students in a timely fashion, may be responsible for perceptions about additional workload as faculty find that there is no "down" time for online teaching.

Workload perceptions also may be affected by environmental differences in how assignments are submitted, evaluated and returned. Assignments submitted as WebCT mail attachments take additional time to open, download, store, evaluate, and return to students, than do assignments submitted in FTF classrooms. Additional time needed for the use of technology was not a variable in this study.

Also not yet considered in this body of literature, is whether or not the construction process affects perceptions of workload once an online course begins. A faculty member who has recently spent hundreds of hours building an online course may have residual emotional issues about that process as they begin teaching. Online course development must be considered in any comparisons of preparation time, since the entire semester must be ready for delivery prior to the start of the term.

This study was extremely limited in its scope and design. It utilized average, rather than actual, typing and reading speeds. Future research might establish actual typing and reading skills for online students and faculty with standardized tests prior to data analysis, providing more validity and reliability to the design. It also did not consider any differences between reading speed for print materials verses reading computer screens. More research is needed to determine if reading speeds are equal between print materials and computer screen presentations at various screen resolutions. This study also assumed that typing and reading skills remained constant through the course. It is conceivable that these skills might improve during the course and diminish workload time for interaction. The study sample was limited to only one institution and only three faculty. Research involving online interaction at several institutions with larger course populations would also strengthen the knowledge in this area. Further research, documenting every interaction necessary for FTF courses would also strengthen future comparisons between the two teaching environments.

This study assumed that students and faculty read their own discussion postings and did not consider proofreading time. It is possible that workload for creating email messages and discussions is much greater than indicated in this study due to proofreading time. It is also unclear how faculty perceptions may differ concerning the mental and physical actions needed for online teaching when compared to FTF classrooms. Typing may be perceived as more strenuous than speaking. Screen reading may be perceived as more physically demanding than listening. Working from home may be perceived as a psychological intrusion on privacy and traditional leisure hours for faculty. 
Pedagogy and course organization also may affect interaction workload. Faculty requirements for discussion participation varied among the instructors in these courses. Workload management for discussions may be controlled to some extent, by the online instructor who sets minimum or maximum participation goals. Well-organized courses with clear instructions for assignments also may result in less confusion among students and further reduce workload for online communication. Online faculty must control their workload dynamics and clearly communicate to students when they can expect responses to mail messages. The online environment may also result in unnecessary student contact.

Online students may need reassurance that there is actually an instructor on the "other end" and require more frequent attention than FTF students.

While increased workload claims for online interaction are not supported by the data in this study, workload dynamics could be clearly seen as more demanding for online than FTF equivalent courses. It is unreasonable to expect any higher education faculty member to be "on-call" twenty-four hours a day, seven days a week. Faculty members should receive compensation for this unique demand on their time, or limit online interactions and course activities to traditional workday hours.

\section{REFERENCES}

1. Carnevale, D. Professors seek compensation for online courses. The Chronicle of Higher Education August 13, 2004. Online: http://chronicle.com/free/v50/i49/49a02701.html.

2. Schifter, C. Compensation models in distance education. Online Journal of Distance Learning Administration 3(1): Spring, 2000. Online: http://www.westga.edu/ distance/ojdla/spring71 /schifter71.html.

3. Lammers, W. and J. Murphy. A profile of teaching techniques used in the university classroom. Active Learning in Higher Education 3(1): 54-67, 2002.

4. Thielens, W. The disciplines and undergraduate lecturing. Paper presented at the annual meeting of the American Educational Research Association, Washington, D.C., 1987.

5. Barab, S., M. Thomas, and H. Merrill. Online learning: From information dissemination to fostering collaboration. Journal of Interactive Learning Research 12(1): 105-133, 2001.

6. Borthick, A. \& D. Jones. The motivation for collaborative discovery learning online and its application in an information systems assurance course. Issues in Accounting Education 15(2): 181210, 2000.

7. Carswell, L., P. Thomas, M. Petre, B. Price, and M. Richards. Distance education via the internet: The student experience. British Journal of Educational Technology 31(1): 29-46, 2000.

8. French, D. A qualitative and quantitative evaluation: Innovative use of internet based collaboration. Paper presented at the Society for Information Technology and Teacher Education International Conference, San Antonio, Texas, 1999.

9. Freeman, M. Flexibility in access, interaction and assessment: The case for web-based teaching programs. Australian Journal of Educational Technology 13(1): 23-39, 1997.

10. Lesh, S., J. Guffey, and L. Rampp. Changes in Student Attitudes Regarding a Web-Based Health Profession Course. United States Research Reports HE032863. Arkansas: Higher Education, 2000.

11. Jiang, M. and E. Ting. A study of students' perceived learning in a web-based online environment. Paper presented at the World Conference of the WWW and the Internet, Honolulu, HI, 1999.

12. Tello, S. Analysis of the relationship between instructional interaction and student persistence in online education. Unpublished Doctoral Dissertation. University of Massachusetts Lowell, 2002.

13. Wu, D. \& S. Hiltz. Online discussions and perceived learning. Paper presented at the Ninth Americas Conference on Information Systems, Tampa, Florida, 2003. 
14. Prammanee, N. Understanding participation in online courses: A case study of perceptions of online interaction: 14, 2004. Online: http://it.coe.uga.edu/itforum/paper68/paper68.html.

15. Lazarus, B. Teaching courses online: How much time does it take? Journal of Asynchronous Learning Networks 7(3): 47-54, 2003.

16. Borthick, A. and D. Jones. The motivation for collaborative discovery learning online and its application in an information systems assurance course. Issues in Accounting Education 15(2): 181210, 2000.

17. Mason, R. Analyzing computer conferencing interactions. International Journal of Computers in Adult Education and Training 2(3): 161-173, 1991.

18. Mouza, C., D. Kaplan, and I. Espinet. A web-based model for online collaboration between distance learning and campus students. Paper presented at the WebNet 2000 World Conference on the WWW and Internet, San Antonio, Texas, 2000.

19. Patterson, N. An evaluation of graduate class interaction in face-to-face and asynchronous computer groupware experiences: A collective case study. Paper presented at the Association for Higher Education Conference, San Antonio, Texas, 1999.

20. Thornam, C. and S. Phillips. Interactivity in online and face-to-face sections of a graduate nursing course. TechTrends 45(1): 34, 2001.

21. Thompson, J., F. Nay, and B. Malone. Utilizing the internet to supplement classroom instruction: An analysis of longitudinal data. Paper presented at the annual meeting of the Mid-Western Education Research Association, Chicago, IL, 2000.

22. Helford, P. and R. Lei. Using the web to deliver and enhance classes: Two case studies. Paper presented at the European University Information Systems International Conference, Espoo, Finland, 1999.

23. Johnson, S., S. Aragon, N. Shaik, and N. Palma-Rivas. Comparative analysis of online vs. faceto-face instruction. Paper presented at the World Conference of the WWW and the Internet, Orlando, Florida, 1999.

24. Cook, R. \& S. Rule. When face to fact won't work: Internet-based focus groups. Unpublished paper presented at the Growing Partnerships for Rural Special Education Conference, San Diego, California, 2001.

25. Gaddis, B., H. Naperikowski, N. Guzman, and R. Muth. A comparison of collaborative learning and audience awareness in two computer-mediated writing environments. Paper presented at the National Convention of the Association for Educational Communications and Technology, Denver, Colorado, 2000.

26. Rodrigues, S. Evaluation of an online masters course in science teacher education. Journal of Education for Teaching 25(3): 263-270, 1999.

27. Hiltz, S. Collaborative learning in asynchronous learning networks: Building learning communities. Paper presented at the World Conference of the WWW and the Internet, Orlando, Florida, 1998.

28. Hilsop, G. Does teaching online take more time? Paper presented at the Frontiers of Education Conference, Reno, NV, 2001.

29. Ostrach, R. Typing speed: How fast is average, 1997. Online: http://www.fivestarstaff.com /publication_typing.htm.

30. Legge, G., C. Madison, and J. Mansfield. Measuring Braille reading speed with the MNREAD test. Visual Impairment Research (1): 131-145, 1999.

\section{ABOUT THE AUTHOR}

Barbara Payne McLain is an Associate Professor of Music and Director of the Online Master's of Arts Degree in Music Education at the University of Hawaii-Manoa. She is an experienced distance educator and received a prestigious WebCT Exemplary Course Award in 2001. Dr. McLain is in frequent demand as a consultant for distance learning and is currently serving as President-Elect of the Western Division of MENC: The National Association for Music Education. 